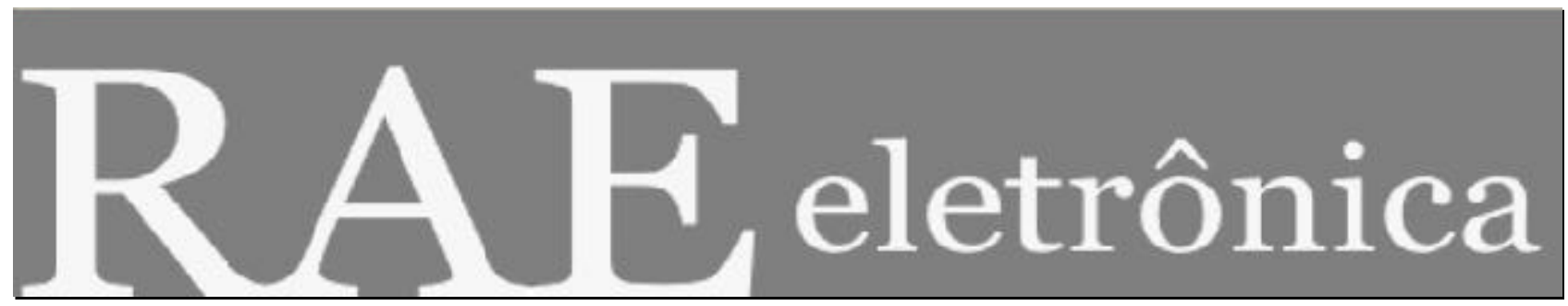

\title{
COMPETÊNCIAS INDIVIDUAIS, MODERNIDADE ORGANIZACIONAL E SATISFAÇÃO NO TRABALHO: UM ESTUDO DE DIAGNÓSTICO COMPARATIVO
}

Por:

\section{Anderson de Souza Sant'anna \\ Lúcio Flávio Renault de Moraes \\ Zélia Miranda Kilimnik}

RAE-eletrônica, v. 4, n. 1, Art. 1, jan./jul. 2005

http://www.rae.com.br/eletronica/index.cfm?F useAction=Artigo \&ID=1696\&Secao=ARTIGOS \&Volu $\mathrm{me}=4 \&$ Numero $=1 \& \mathrm{Ano}=2005$

CCopyright, 2005, RAE-eletrônica. Todos os direitos, inclusive de tradução, são reservados. É permitido citar parte de artigos sem autorização prévia desde que seja identificada a fonte. A reprodução total de artigos é proibida. Os artigos só devem ser usados para uso pessoal e nãocomercial. Em caso de dúvidas, consulte a redação: raeredacao@fgvsp.br.

A RAE-eletrônica é a revista on-line da FGV-EAESP, totalmente aberta e criada com o objetivo de agilizar a veiculação de trabalhos inéditos. Lançada em janeiro de 2002, com perfil acadêmico, é dedicada a professores, pesquisadores e estudantes. Para mais informações consulte o site www.rae.com.br/eletronica. 


\title{
COMPETÊNCIAS INDIVIDUAIS, MODERNIDADE ORGANIZACIONAL E SATISFAÇÃO NO TRABALHO: UM ESTUDO DE DIAGNÓSTICO COMPARATIVO
}

\section{RESUMO}

Este trabalho se propõe a relatar procedimentos e resultados de validação de escalas destinadas à mensuração dos construtos Competências Individuais Requeridas, Modernidade Organizacional e Satisfação no Trabalho. Visa, também, diagnosticá-los junto a uma amostra de 654 profissionais da área da Administração. Utilizando técnicas estatísticas multivariadas e descritivas, o estudo adotou como referenciais teóricos, a Abordagem de Avaliação da Modernidade Organizacional (EBOLI, 1996), o Modelo das Dimensões Básicas da Tarefa (HACKMAN e OLDHAM, 1975) e uma revisão de abordagens anglo-americana e francesa sobre a Competência. Como resultados, há que se destacar a validação das escalas propostas, assim como a percepção dos profissionais alvo do estudo quanto a elevado grau de demanda pelo conjunto das competências investigadas vis-à-vis graus moderados de modernidade organizacional e satisfação no trabalho.

\section{PALAVRAS-CHAVE}

Competências individuais, modernidade organizacional, satisfação no trabalho, validação de escalas, análise multivariada.

\begin{abstract}
This study proposes to describe proceedings and results of validation of the measures adopted to measure the variables Individual Competencies Required, Organizational Modernity and Satisfaction at Work, as well as to diagnose them among 654 professional investigated. With that aim, statistical techniques (multivariate and descriptive methods) for the data processing were used. The Evaluation Approach of Organizational Modernity (EBOLI, 1996), the Motivation and Job Satisfaction Model (HACKMAN e OLDHAM, 1975) and a review the Anglo-Saxon and French approaches on competence were employed as theoric referential. As for results, we could validate the proposed scales to measure the variables significant to this study. As products of the diagnosis drawn among the researched professionals, the respondent's perceptions to a higher degree of demand for the investigated competencies aspect and also moderate levels of organizational modernity and job satisfaction, amongst other aspects, deserve prominence.
\end{abstract}

\section{KEYWORDS}

Individual competencies, organizational modernity, satisfaction at work, validation of measures, multivariate analyses. 


\section{INTRODUÇÃO}

Conforme salientam Marquardt e Engel (1993), em nenhuma outra época na história das organizações, as pessoas com suas competências e talentos foram tão valorizadas como atualmente. De fato, se há um ponto em relação ao qual poucos se opõem é que, com o intuito de fazerem frente às atuais transformações do mundo dos negócios, as empresas têm necessitado de indivíduos cada vez mais talentosos e competentes.

Para autores como Pucik, Thichy e Barnett (1992), Prahalad e Hamel (1990) e Bartlett e Ghoshal (1987), na medida em que fontes tradicionais de vantagem competitiva, tais como tecnologia e mão-deobra barata, não mais se revelam suficientes para proverem uma posição competitiva sustentável, os indivíduos e suas competências passam a ser enfatizados como elementos centrais de diferenciação estratégica.

Corroborando essa visão, Bartlett e Ghoshal (1987) chegam mesmo a afirmar que as organizações, que agora concorrem entre si por clientes e mercados, em escala jamais vista, têm sido levadas a competirem também pelo recurso elevado à categoria de o mais importante de todos: o talento humano.

Nesse contexto seria de se esperar reflexos positivos para os trabalhadores no que se refere a um maior enriquecimento de suas tarefas, assim como uma participação mais ativa, quer produtiva, quer salarialmente. No entanto, na prática, será isso que se constata? Em outras palavras, a gestão das organizações, em especial a gestão de seus recursos humanos, tem propiciado as condições necessárias ao desenvolvimento e efetiva aplicação das novas competências individuais demandadas, com contrapartidas para os trabalhadores em termos de melhores condições de trabalho e maior satisfação no e com o mesmo?

Tendo por base tal problemática, buscou-se, após validação das escalas propostas para mensuração dos construtos objeto deste estudo - Competências Individuais Requeridas, Modernidade Organizacional e Satisfação no Trabalho - diagnosticá-los junto a uma amostra de profissionais da área de Administração, com vistas a melhor compreender: (1) o grau em que as organizações a que se vinculam tais profissionais têm requerido novas competências individuais consideradas chave para o enfrentamento do novo ambiente dos negócios; (2) a adequação entre a difusão desse discurso e o grau em que os sistemas de gestão das organizações em que atuam os mesmos favorecem e sustentam a formação e aplicação das novas competências requeridas; (3) a percepção dos profissionais pesquisados quanto a fatores de contexto e conteúdo do trabalho, considerados por diversos autores, dentre eles, Werther e Davis (1983), Hackman e Oldham (1975), como determinantes de satisfação no e com o trabalho.

Para tal, foi realizada pesquisa de natureza quantitativa, por meio da técnica de Survey, utilizando-se para coleta de dados questionário composto de questões medidas por escalas do tipo Likert .

Como referencial teórico, fez-se uso da Abordagem de Análise dos Padrões de Modernidade Organizacional, proposta por Eboli (1996), do Modelo das Dimensões Básicas da Tarefa, elaborado por Hackman e Oldham (1975) e de revisão dos principais estudos anglo-americanos e franceses sobre a Competência, por meio buscou-se identificar as competências individuais mais enfaticamente requeridas aos trabalhadores, como resposta às novas demandas do atual ambiente dos negócios. 


\section{REFERENCIAL TEÓRICO}

\section{Competências Individuais Requeridas}

O conceito de competência não é recente. Na verdade, trata-se de uma idéia consideravelmente antiga, porém (re-)conceituada e (re-)valorizada no presente em decorrência de fatores como os processos de reestruturação produtiva em curso, a intensificação das descontinuidades e imprevisibilidades das situações econômicas, organizacionais e de mercado e as sensíveis mudanças nas características do mercado de trabalho, resultantes, em especial, dos processos de globalização (FLEURY e FLEURY, 2001).

Diversas, no entanto, têm sido as definições atribuídas à expressão competência individual. A inexistência de um consenso quanto a seu conceito, além de divergências de caráter filosófico e ideológico podem, também, ser atribuídas à adoção da expressão com diferentes enfoques, em diferentes áreas do conhecimento (MANFREDI, 1998).

Não obstante a inexistência de um consenso quanto a seu conceito, alguns pontos comuns em relação a essa noção podem ser identificados. Em primeiro lugar, a competência é comumente apresentada como uma característica ou conjunto de características ou requisitos - saberes, conhecimentos, aptidões, habilidades - indicados como condição capaz de produzir efeitos de resultados e/ou solução de problemas (SPENCER e SPENCER, 1993; BOYATZIS, 1982; MCCLELLAND e DAILEY,1972).

Outro ponto comum às diversas acepções contemporâneas de competência é a elevada conformidade desse conceito com o discurso empresarial vigente, bem como com as demandas advindas dos processos de reestruturação e de modernização produtiva em voga (HIRATA, 1994; SHIROMA e CAMPOS, 1997; STROOBANTS, 1997).

Partindo, portanto, da compreensão da competência como uma resultante da combinação de múltiplos saberes - saber-fazer, saber-agir, saber-ser - capazes de propiciarem respostas efetivas aos desafios advindos do atual contexto dos negócios, adotoutse para identificação das competências individuais mais enfaticamente requeridas pelas organizações contemporâneas, uma extensa revisão das abordagens anglo-americana - destacando-se trabalhos de autores como Spencer e Spencer (1993), Boyatzis (1982) e Mcclelland e Dailey (1972) - e francesa - considerando, dentre outros, os estudos de Zarifian, (2001) Perrenoud (2001), Dubar (1998), Stroobants (1997), Le Bortef (1994).

Como resultado, foi selecionado, por meio da técnica de análise de conteúdo por categoria, proposta por Richardson et al. (1985), um elenco de quinze competências mais reiteradamente apontadas nos trabalhos revisados, a saber: domínio de novos conhecimentos técnicos associados ao exercício do cargo ou função ocupada; capacidade de aprender rapidamente novos conceitos e tecnologias; criatividade; capacidade de inovação; capacidade de comunicação; capacidade de relacionamento

interpessoal; capacidade de trabalhar em equipes; autocontrole emocional; visão de mundo ampla e global; capacidade de lidar com situações novas e inusitadas; capacidade de lidar com incertezas e ambigüidades; iniciativa de ação e decisão; capacidade de comprometer-se com os objetivos da organização; capacidade de gerar resultados efetivos e capacidade empreendedora. 


\section{Modernidade organizacional}

Em termos históricos, o conceito de modernidade pode ser introduzido a partir de determinadas caracterizações - o mito da tecnologia, o domínio da razão científica, a idéia de progresso, a exaltação da democracia - que a diferencia de períodos ou fases anteriores da humanidade, como o mundo primitivo, o mundo antigo e o mundo medieval (ZAJDSZNAJDER, 1993).

Para Touraine (1994), a noção de modernidade resulta de duas grandes correntes de pensamento: de um lado, o racionalismo greco-romano, retomado pelos humanistas da Renascença; de outro, a concepção cristã de alma, secularizada por meio da noção de sujeito.

Para o autor, no entanto, durante muito tempo a modernidade foi definida apenas pela eficácia da racionalidade instrumental, ignorando o elemento humano como liberdade e como criação. Dessa redução, salienta Touraine (1994), decorreram os fundamentos de sua crise, cuja superação - e estabelecimento de uma nova modernidade - pressupõe o resgate de sua outra metade: o sujeito.

Sob essa perspectiva, a modernidade, no seu sentido estrito, pode ser compreendida como um redirecionar do homem para o centro da sociedade, contemplando suas várias dimensões: tecnológica (combinando racionalização e subjetivação); social (na medida em que a subjetivação só é possível por meio do movimento social); política (visto que a democracia é o regime que permite a expressão política do indivíduo); e cultural (uma vez que valores de liberdade e eficácia se encontram em sua origem).

Eboli (1996), fundamentada nas idéias de Touraine (1994), mas agregando, também, perspectivas de pesquisadores nacionais como Buarque (1994), Zajdsznajder (1993), Faoro (1992) e Motta (1992), propõe uma transposição da abordagem daquele autor para o contexto organizacional. Como resultado, estabelece um conjunto de indicadores abrangendo as dimensões cultural, política, social, administrativa, econômica e tecnológica das organizações.

Calcado na abordagem proposta por essa autora, o estudo contemplou, como ponto de partida para a avaliação do grau de modernidade organizacional, os seguintes aspectos: grau em que a organização valoriza a iniciativa, a responsabilidade e a liberdade; grau em que a organização cultiva um clima interno que favorece mudanças, inovação e aprendizagem; grau em que a organização adota um regime democrático; grau em que a organização tem um processo decisório descentralizado e democrático; grau em que a organização estimula a autonomia, a iniciativa de ação e de decisão; grau em que a organização encoraja a interação social; grau em que a organização estimula a participação das pessoas nos processos organizacionais; grau em que a organização favorece que as pessoas se mantenham informadas e que atinjam seus objetivos, materiais ou psicológicos; grau em que a organização tem claramente definidos sua missão, objetivos, estratégias e metas; grau em que as tecnologias, políticas e práticas promovem a tomada de risco, a criatividade, a eficácia e o desempenho das pessoas; grau em que os objetivos econômicos da organização subordinam-se a objetivos sociais e princípios éticos; grau em que a tecnologia empregada favorece a interação entre pessoas e áreas; grau em que a organização combina de forma equilibrada a utilização de tecnologias avançadas, com a criatividade das pessoas. 


\section{A Satisfação no Trabalho}

Para a análise da extensão na qual os profissionais pesquisados "gostam e sentem prazer com o que fazem" (QUARSTEIN, McAFEE e GLASSMAN, 1992, p. 859), foi utilizado como referência o Modelo das Dimensões Básicas da Tarefa, proposto por Hackman e Oldham (1975).

Centrando no conteúdo do trabalho como determinante da satisfação no e com o mesmo, os autores defendem a idéia de que determinadas características quando presentes nas tarefas desempenhadas pelos trabalhadores promovem a emergência de determinados estados psicológicos críticos capazes de determinar a motivação e a satisfação no trabalho.

O primeiro desses estados é definido como a significância percebida ou o grau com que o sujeito vê seu trabalho como importante, valioso e significativo, dentro de sua escala de valores. O segundo refere-se à responsabilidade percebida pelo trabalhador em relação a seu trabalho, isto é, ao grau em que o profissional se sente responsável pelos resultados do trabalho que executa. Já o terceiro, diz respeito ao conhecimento dos resultados do trabalho, ou seja, ao grau em que o indivíduo conhece e entende seu desempenho efetivo na tarefa.

Para os autores, as dimensões da tarefa, presentes em seu modelo, e cuja presença seriam capazes de levar à manifestação desses estados psicológicos críticos são: variedade de habilidades; identidade da tarefa; significado da tarefa; autonomia; feedback extrínseco; feedback do próprio trabalho e interrelacionamento.

Hackman e Oldham (1975), embora considerem que as variáveis de conteúdo são as principais determinantes da satisfação no trabalho não deixam de reconhecer a importância dos fatores de contexto, destacando-se variáveis tais como: a possibilidade de crescimento, a supervisão, a segurança no trabalho, a compensação financeira e o ambiente social (MORAES e KILIMNIK, 1989).

Além de fatores propostos por Hackman e Oldham (1975), o estudo contemplou também itens da escala de mensuração da satisfação no trabalho, proposta por Cooper, Sloan e Williams (1988), as quais buscaram investigar a satisfação dos profissionais pesquisados com fatores organizacionais. São eles: a comunicação e modo como as informações circulam na empresa, o modo como os conflitos são resolvidos na organização e a maneira como as mudanças e inovações são implementadas na empresa.

A seguir são descritos procedimentos utilizados para a formatação, análise semântica e aplicação do instrumento de coleta de dados proposto para mensuração dos construtos de interesse deste estudo.

\section{FORMATAÇÃO, ANÁLISE SEMÂNTICA E APLICAÇÃO DO INSTRUMENTO DE COLETA DE DADOS}

Com base no referencial teórico formatourse um questionário composto, originalmente, por 70 itens, medidos por escalas do tipo Likert, de 11 pontos, o qual foi submetido à análise por três doutores na 
área do Comportamento Humano nas Organizações, com o objetivo de avaliar se as escalas e itens considerados mostravam-se aderentes, sob a perspectiva teórica, à proposta de mensuração dos construtos alvo do estudo.

Concomitantemente, o instrumento de coleta de dados foi submetido a um pré-teste, envolvendo 30 respondentes selecionados junto à população da pesquisa. Segundo Easterby-Smith et al. (1991), a realização de tal procedimento revela-se significativo ao permitir verificar, a priori, se os itens do instrumento são compreensíveis, se a sequiência das questões encontra-se bem delineada e se há itens sensíveis.

Cumpridas essas etapas e procedidas as alterações necessárias, o instrumento foi aplicado a uma amostra de 1.000 profissionais, de um universo de 1.510 trabalhadores que, por ocasião da coleta de dados, encontravam-se cursando programas de pós-graduação lato-sensu em Administração, junto a instituições de ensino superior de Belo Horizonte (MG).

Dos 1.000 questionários distribuídos obteve-se como retorno 885 instrumentos preenchidos. Convém salientar que o elevado percentual de questionários devolvidos $(88,5 \%)$ explica-se, sobretudo, pela estratégia de coleta de dados utilizada, a qual se centrou na aplicação do instrumento durante a realização das sessões dos cursos, sob a presença do pesquisador.

Finalmente, vale observar que para a composição final da amostra foram expurgados questionários com dados ausentes e com valores extremos (outliers), segundo critérios recomendados por Hair et al. (1998), conforme relatado a seguir.

\section{ANÁLISE DAS PROPRIEDADES PSICOMÉTRICAS DAS ESCALAS}

Neste item são apresentados procedimentos e resultados dos cálculos utilizados para a validação das escalas propostas: verificação da dimensionalidade, por meio da aplicação da técnica de análise fatorial exploratória e análise da confiabilidade, por meio do cálculo do coeficiente alfa de Cronbach.

Seguindo recomendações de autores como Hair Jr. et al. (1998) e Tabachnick e Fidell (2001) quanto à relevância da verificação dos dados coletados preliminarmente à adoção de técnicas estatísticas multivariadas - como a análise fatorial exploratória - foram levadas a efeito análises de dados ausentes e de valores extremos uni e multivariados.

Segundo Hair Jr. et al. (1998, p. 38), dados ausentes podem ser definidos como uma "informação não disponível a respeito de uma pessoa (ou caso) sobre a qual outras informações estão disponíveis". Cabe salientar, no entanto, que a grande dificuldade gerada pela presença de um dado ausente refere-se aos vieses em que sua exclusão pode resultar, quando não precedida uma análise de sua aleatoriedade. Autores como Tabachnick e Fidell (2001) destacam, todavia, que tal análise pode ser dispensada quando o percentual de dados ausentes, por variável, revelar-se inferior a 5\% do total de casos. 
Assim sendo, com vistas à análise de dados ausentes, foi calculada a distribuição de frequiência dos indicadores pesquisados. Como resultado obteve-se que, comparativamente ao total de casos, todas as variáveis pesquisadas apresentaram percentuais de dados ausentes inferiores a 5\%. Diante disso, os 43 casos em que os mesmos foram observados puderam ser excluídos, sem riscos de vieses consideráveis à análise.

Já no que tange às observações cujas características revelavam-se destoantes daquelas apresentadas pelo conjunto dos dados obtidos (dados extremos), adotouse, igualmente, os critérios recomendados por Hair Jr. et al. (1998). Desse modo, em relação aos dados extremos univariados, foram excluídas as 98 observações cujos valores dos escores $z$ das variáveis encontravam-se fora do intervalo $[-3,00$; $3,00]$.

Para a análise dos valores extremos multivariados, por sua vez, considerourse o cálculo da distância de Mahalanobis $\left(\mathrm{D}^{2}\right)$, seguido de análise de regressões stepwise de cada um dos casos identificados com vistas a se investigar os indicadores que os provocaram. Como resultado pôde-se suprimir as 90 observações identificadas com dados extermos multivariados, resultando, ao final, uma amostra de 654 observações.

Isto feito, foram efetuadas verificações da normalidade uni (teste Kolmogorov-Smirnov) e multivariada (teste de MARDIA), linearidade (coeficiente de correlação produto-momento de Pearson), multicolinearidade (Collinearity Diagnostics), singularidade (tendo em vista que as análises realizadas, utilizando o pacote estatístico AMOS 4.0, não apresentaram quaisquer mensagens de erro, concluiu-se pela inexistência de singularidade entre os indicadores constantes das escalas propostas) e homocesdasticidade (como foram consideradas apenas variáveis contínuas em dados não agrupados, partiu-se do princípio que o pressuposto da homocesdaticidade encontrava-se atendido), apontadas por Hair Jr. et al. (1998) como premissas importantes à aplicação de técnicas de análise multivariada.

Como resultados, cabe salientar que não foi possível verificar, pelos testes de Kolmogorov-Smirnov e MARDIA, as premissas de normalidade uni e multivarida, não obstante cálculo da estatística de MARDIA (PK<3), realizado por meio do software LISREL 8.3, tenha indicado a aceitação da hipótese de existência de normalidade multivariada. Convêm destacar, ainda, a exclusão de variáveis originalmente constantes das escalas propostas, a fim de se assegurar o atendimento às demais premissas analisadas.

Concluída a análise exploratória dos dados, bem como de premissas à análise multivariada, são apresentados, no próximo item, procedimentos e resultados da avaliação da dimensionalidade das escalas propostas, procedidas por meio da técnica de análise fatorial exploratória.

\section{Análise fatorial exploratória}

Segundo Tabachnick e Fidell (2001), a análise fatorial exploratória é uma técnica estatística aplicada a um conjunto de variáveis quando o pesquisador está interessado em descobrir quais formam subconjuntos coerentes e relativamente independentes uns dos outros.

Para Hair Jr. et al. (1998), a análise fatorial exploratória se presta a diversos propósitos, dentre eles a análise da dimensionalidade das medições. Nesse caso, a suposição é que todas as variáveis constantes das escalas podem ser agrupadas em fatores que garantam a unidimensionalidade das medidas. 
Um segundo objetivo da análise fatorial exploratória é verificar se todos os indicadores constantes das medições são realmente relevantes para a pesquisa. Segundo Hair Jr. et al. (1998), essa relevância pode ser constatada de cinco maneiras.

A primeira, é a verificação das correlações entre os indicadores. Para Hair Jr. et al. (1998) a presença de indicadores relevantes encontra-se associada a um número expressivo de correlações bivariadas superiores a 0,30. A segunda maneira é se verificar a medida de adequação da amostra, obtida por meio do teste Kaiser-Meier-Olkin - KMO. Contido no intervalo [0, 1], quanto mais próximo de 1 (um) for o valor obtido, melhor a adequação da amostra. A terceira maneira consiste na verificação dos valores da matriz de antiimagem, os quais devem ser pequenos. A quarta forma, por sua vez, baseia-se na análise da comunalidade dos indicadores, medida que indica o grau em que os itens encontram-se associados à combinação linear gerada pelo fator extraído. Finalmente, a quinta maneira é a análise da carga dos indicadores. No caso deste estudo, baseando-se nas recomendações de Hair Jr. et al. (1998) e no observado em estudos realizados, no Brasil, por Borges-Andrade (1995), Borges-Andrade et. al. (1996), Oliveira-Castro et. al. (1998), foi considerado como ponto de corte cargas iguais ou superiores a 0,30 .

Cabe mencionar, ainda, a adoção, para o cálculo das variâncias dos fatores extraídos, do critério da raiz latente, bem como a utilização do método Oblimin, para análise dos coeficientes dos indicadores constantes dos fatores obtidos.

Como resultado final das análises fatoriais procedidas, os quinze indicadores destinados à mensuração das competências individuais requeridas puderam ser agrupados em um único fator, conforme apresentado no QUADRO 1.

\section{Quadro 1 - Agrupamento de indicadores por fator - Competências Individuais Requeridas}

\begin{tabular}{|c|c|}
\hline \multirow{15}{*}{$\begin{array}{l}\text { Competências Individuais } \\
\text { Requeridas }\end{array}$} & $\begin{array}{l}\text { Capacidade de aprender rapidamente novos conceitos e } \\
\text { tecnologias }\end{array}$ \\
\hline & Capacidade de trabalhar em equipes \\
\hline & Criatividade \\
\hline & Visão de mundo ampla e global \\
\hline & $\begin{array}{lllllll}\begin{array}{l}\text { Capacidade } \\
\text { organização }\end{array} & \text { de comprometer-se } & \text { com } & \text { os objetivos } & \text { da } \\
\end{array}$ \\
\hline & Capacidade de comunicação \\
\hline & Capacidade de lidar com incertezas e ambigüidades \\
\hline & $\begin{array}{l}\text { Domínio de novos conhecimentos técnicos associados ao } \\
\text { exercício do cargo ou função ocupada }\end{array}$ \\
\hline & Capacidade de inovação \\
\hline & Capacidade de relacionamento interpessoal \\
\hline & Iniciativa de ação e decisão \\
\hline & Autocontrole emocional \\
\hline & Capacidade empreendedora \\
\hline & Capacidade de gerar resultados efetivos \\
\hline & Capacidade de lidar com situações novas e inusitadas. \\
\hline
\end{tabular}

FONTE - Dados da pesquisa 
Já os indicadores de modernidade organizacional puderam ser agrupados em três fatores, denominados Modernidade Administrativa e das Práticas de Gestão de Pessoas, Modernidade Política e Modernidade

Cultural (QUADRO 2).

\section{Quadro 2 - Indicadores por fator - Modernidade Organizacional}

\begin{tabular}{|c|c|}
\hline \multirow{12}{*}{$\begin{array}{l}\text { Modernidade } \\
\text { Administrativa e } \\
\text { das Práticas de } \\
\text { Gestão de Pessoas }\end{array}$} & $\begin{array}{l}\text { O sistema de remuneração da organização recompensa os atos de } \\
\text { competência }\end{array}$ \\
\hline & A organização é fortemente orientada para resultados \\
\hline & $\begin{array}{l}\text { Há um sistema de avaliação que permite diferenciar o bom e o mau } \\
\text { desempenho }\end{array}$ \\
\hline & $\begin{array}{l}\text { A organização equilibra adequadamente a preocupação com } \\
\text { resultados financeiros, com as pessoas e com a inovação }\end{array}$ \\
\hline & $\begin{array}{l}\text { As políticas e práticas de recursos humanos estimulam as pessoas a se } \\
\text { preocuparem com a aprendizagem contínua }\end{array}$ \\
\hline & $\begin{array}{l}\text { Os principais critérios para promoção são a competência e a } \\
\text { produtividade da pessoa }\end{array}$ \\
\hline & $\begin{array}{l}\text { A organização combina de forma equilibrada a utilização de } \\
\text { tecnologias avançadas com a criatividade das pessoas }\end{array}$ \\
\hline & A tecnologia empregada favorece a interação entre pessoas e áreas \\
\hline & $\begin{array}{l}\text { As políticas e práticas da organização estimulam que as pessoas } \\
\text { estejam sempre bem informadas e atualizadas }\end{array}$ \\
\hline & $\begin{array}{l}\text { A estratégia, missão, objetivos e metas da organização são claramente } \\
\text { definidos }\end{array}$ \\
\hline & $\begin{array}{l}\text { As políticas e práticas de recursos humanos da organização estimulam } \\
\text { o desenvolvimento pessoal e profissional }\end{array}$ \\
\hline & $\begin{array}{l}\text { De modo geral, os empregados sabem o que devem fazer para } \\
\text { colaborar com os objetivos da organização }\end{array}$ \\
\hline \multirow{7}{*}{$\begin{array}{l}\text { Modernidade } \\
\text { Política }\end{array}$} & O processo decisório na organização é descentralizado \\
\hline & A organização favorece a autonomia para tomar decisões \\
\hline & $\begin{array}{l}\text { No que se refere ao aspecto político, o regime que vigora na } \\
\text { organização pode ser caracterizado como democrático }\end{array}$ \\
\hline & Os processos de tomada de decisão são participativos e transparentes \\
\hline & $\begin{array}{l}\text { A organização conta com sistemas de gestão participativos que } \\
\text { estimulam a iniciativa e ação das pessoas }\end{array}$ \\
\hline & $\begin{array}{l}\text { A organização admite a diversidade de comportamentos e respeita as } \\
\text { diferenças individuais }\end{array}$ \\
\hline & $\begin{array}{l}\text { O ambiente de trabalho facilita o relacionamento entre as pessoas, } \\
\text { mesmo de níveis hierárquicos diferentes }\end{array}$ \\
\hline \multirow{4}{*}{$\begin{array}{l}\text { Modernidade } \\
\text { Cultural }\end{array}$} & O clima interno da organização estimula idéias novas e criativas \\
\hline & $\begin{array}{l}\text { O clima interno da organização estimula que as pessoas estejam em } \\
\text { contínuo processo de aprendizagem, no seu dia-a-dia de trabalho }\end{array}$ \\
\hline & $\begin{array}{l}\text { Na organização há um clima estimulante para que as pessoas realizem } \\
\text { suas atividades, buscando se superar }\end{array}$ \\
\hline & A organização encoraja a iniciativa e responsabilidade individual \\
\hline
\end{tabular}

FONTE - Dados da pesquisa. 
De forma similar, os indicadores de satisfação no trabalho foram agrupados em três fatores: Satisfação com Fatores Associados ao Trabalho em Si, Satisfação com Fatores Organizacionais e Satisfação com a Gerência (QUADRO 3).

\section{Quadro 3 - Indicadores por fator - Satisfação no Trabalho}

\begin{tabular}{|c|c|}
\hline \multirow{8}{*}{$\begin{array}{l}\text { Satisfação com } \\
\text { Fatores associados } \\
\text { ao Trabalho em Si }\end{array}$} & $\begin{array}{l}\text { A liberdade de pensamento e ação que eu tenho ao fazer o meu } \\
\text { trabalho }\end{array}$ \\
\hline & $\begin{array}{l}\text { Meu trabalho me fornece consideráveis oportunidades de } \\
\text { independência e liberdade sobre como executá- lo }\end{array}$ \\
\hline & $\begin{array}{l}\text { O grau em que aplico no dia-a-dia do meu trabalho os conhecimentos } \\
\text { adquiridos ao longo de minha formação acadêmica } \\
\text { A possibilidade de crescimento pessoal e de desenvolvimento que eu } \\
\text { tenho ao realizar o meu trabalho }\end{array}$ \\
\hline & $\begin{array}{l}\text { Meu trabalho exige que eu utilize diversas habilidades complexas e de } \\
\text { alto nível }\end{array}$ \\
\hline & $\begin{array}{l}\text { O grau de participação que me é permitido nas decisões importantes } \\
\text { em relação ao meu trabalho }\end{array}$ \\
\hline & A oportunidade de ajudar outras pessoas enquanto estou trabalhando \\
\hline & O volume de trabalho que eu tenho que realizar \\
\hline & $\begin{array}{l}\text { A simples execução das tarefas do meu trabalho oferece muitas } \\
\text { oportunidades (feedbacks) para mostrar a mim mesmo(a) se o estou } \\
\text { realizando bem ou não }\end{array}$ \\
\hline \multirow{3}{*}{$\begin{array}{l}\text { Satisfação com } \\
\text { Fatores } \\
\text { Organizacionais }\end{array}$} & O modo como os conflitos são resolvidos na organização \\
\hline & $\begin{array}{l}\text { A maneira como as mudanças e inovações são implementadas na } \\
\text { empresa }\end{array}$ \\
\hline & $\begin{array}{l}\text { As comunicações e o modo como as informações circulam na } \\
\text { organização }\end{array}$ \\
\hline \multirow{2}{*}{$\begin{array}{l}\text { Satisfação com a } \\
\text { Gerência }\end{array}$} & $\begin{array}{l}\text { A forma como os meus esforços são valorizados pela organização } \\
\text { Os meus superiores quase nunca me dizem como estou me saindo na } \\
\text { execução do meu trabalho }\end{array}$ \\
\hline & $\begin{array}{l}\text { Comumente os meus superiores me falam sobre o que eles pensam a } \\
\text { respeito do meu desempenho no trabalho }\end{array}$ \\
\hline
\end{tabular}

FONTE - Dados da pesquisa.

Na seqüência são apresentamos os procedimentos e resultados das análises destinadas à verificação da confiabilidade das escalas propostas. 


\section{Análise da confiabilidade das escalas}

Segundo Malhotra (1996), uma escala pode ser considerada confiável quando sua aplicação, em sucessivas medições, resulta em resultados consistentes. Já para Churchill (1995), a confiabilidade de uma escala refere-se ao grau em que a mesma se encontra livre de erros aleatórios.

Neste estudo, como medida para a mensuração da confiabilidade das medidas analisadas adotourse o coeficiente alfa de Cronbach, considerado por Malhotra (1993), Nunally e Berstein (1994) e Hair Jr. et al. (1998), indicador consistente para análise da confiabilidade de uma escala.

Para Hair Jr. et al. (1998), muito embora não haja um padrão absoluto, valores de alfa de Cronbach iguais ou superiores a 0,70 refletem uma fidedignidade aceitável. Por outro lado, salientam que valores inferiores a 0,70 podem ser aceitos se a pesquisa for de natureza exploratória. De forma similar, Nunnaly e Bernstein (1994) apontam como aceitáveis valores de alfa de Cronbach iguais ou superiores a 0,70. Já Malhotra (1996) reconhece como aceitáveis valores de corte iguais ou superiores a 0,60.

Considerando como valor de corte coeficientes alfa de Cronbach iguais ou superiores a 0,70, são apresentados, na TAB. 1, os resultados para os fatores obtidos como produtos finais das análises fatoriais procedidas.

Tabela 1 - Análise de confiabilidade das escalas

\begin{tabular}{|l|c|}
\hline \multicolumn{1}{|c|}{ Fatores } & $\begin{array}{c}\text { Coeficiente alfa de } \\
\text { Cronbach }\end{array}$ \\
\hline Competências Individuais Requeridas & 0,93 \\
\hline Modernidade Administrativa e das Práticas de Gestão de Pessoas & 0,94 \\
\hline Modernidade Política & 0,92 \\
\hline Modernidade Cultural & 0,92 \\
\hline Satisfação com fatores associados ao Trabalho em Si & 0,84 \\
\hline Satisfação com fatores Organizacionais & 0,87 \\
\hline Satisfação com a Gerência & 0,70 \\
\hline
\end{tabular}

FONTE - Dados da pesquisa.

A partir dos resultados da TAB. 1 verifica-se que todas as medidas ficaram dentro do nível $(0,70)$ recomendado por Hair Jr. et al. (1998) e Nunnaly e Bernstein (1994). Vale salientar que, para o conjunto dos coeficientes obtidos, somente para a escala de modernidade cultural a retirada de algum item (A organização encoraja a iniciativa e responsabilidade individual) elevaria o valor do coeficiente: de 0,9182 para 0,9246. Como, no entanto, o valor do coeficiente originalmente obtido já se revelava expressivo, optou-se pela sua manutenção.

A partir do conjunto de cálculos foi possível considerar como fidedignas as escalas propostas para a mensuração dos construtos alvo deste estudo. Validadas as escalas, procede-se, a seguir, à análise descritiva dos dados obtidos junto aos profissionais pesquisados. 


\section{APRESENTAÇÃO DESCRITIVA DOS RESULTADOS}

\section{Descrição das variáveis demográficas, profissionais e organizacionais}

O conjunto dos dados demográficos indica um perfil de respondentes que pode ser caracterizado como jovem (51,8\% na faixa entre 26 e 35 anos e $16,6 \%$ com até 25 anos), ocupante de cargos gerenciais $(41,0 \%)$ ou de nível técnico especializado $(31,0 \%)$, notadamente em áreas de suporte (staff) $(45,6 \%)$ e com formação básica em cursos no campo das ciências sociais aplicadas (59,8\%). Constata-se, ainda, um equilíbrio entre o percentual de homens $(51,5 \%)$ e mulheres $(48,5 \%)$, bem como entre casados $(50,4 \%)$ e solteiros $(44,7 \%)$.

Um outro aspecto a ser destacado refere-se à predominância de profissionais com pouco tempo de serviço na atual organização (45,6\% declarou ter entre 1 e 5 anos de casa, $17,6 \%$ menos de um ano e $16,4 \%$ entre 6 e 10 anos), bem como no atual cargo (52,2\% indicou o estar exercendo entre 1 e 5 anos, $20,8 \%$ há menos de um ano, 15,3\% entre 6 e 10 anos, 8,2\% entre 11 e 15 anos, 2,3\% entre 16 e 20 anos e 1,2\% há mais de 20 anos), achados, os quais, podem estar associados ao perfil jovem da amostra.

Visando compor, por sua vez, uma síntese do perfil das organizações em que atuam tais profissionais, vale salientar o elevado percentual de pesquisados em organizações de serviços $(68,2 \%)$. Cabe apontar, também, a predominância de respondentes oriundos de empresas com mais de 500 empregados $(55,5 \%)$ e com controle privado nacional $(48,3 \%)$ ou estatal $(33,9 \%)$.

\section{Avaliação das competências individuais requeridas}

Previamente à descrição dos resultados, vale esclarecer que a mensuração das competências individuais requeridas, do grau de modernidade organizacional e de satisfação no trabalho baseou-se em questões dispostas em escala Likert de 11(onze) pontos, abrangendo opções de resposta no intervalo de [0, 10], em que quão mais próximo do limite superior da escala, maior o grau de demanda pelas competências investigadas, assim como maior o grau de modernidade das políticas e práticas de gestão e de satisfação com o trabalho.

Tendo por base tais critérios, os dados obtidos revelam uma elevada percepção dos profissionais amostrados quanto à demanda pelas competências avaliadas, evidenciando-se como mais requeridas aquelas diretamente associadas a aspectos relacionais e sociais, bem como a fatores associados à performance das organizações (TAB. 2). 
Tabela 2 - Análise descritiva - Competências Individuais Requeridas

\begin{tabular}{|l|c|c|c|c|}
\hline $\begin{array}{l}\text { Modernidade Administrativa e das Práticas } \\
\text { de Gestão de Pessoas }\end{array}$ & \multicolumn{4}{|c|}{ Medidas Descritivas } \\
\cline { 2 - 5 } & Mínimo & Mediana & Máximo & d.p. \\
\hline Capacidade de gerar resultados efetivos. & 3,0 & 9,0 & 10,0 & 1,6 \\
\hline $\begin{array}{l}\text { Capacidade de se comprometer com os } \\
\text { objetivos da organização. }\end{array}$ & 3,0 & 9,0 & 10,0 & 1,5 \\
\hline Capacidade de trabalhar em equipes. & 2,0 & 9,0 & 10,0 & 1,7 \\
\hline Capacidade de relacionamento inter-pessoal. & 3,0 & 9,0 & 10,0 & 1,5 \\
\hline Capacidade de comunicação. & 3,0 & 9,0 & 10,0 & 1,6 \\
\hline $\begin{array}{l}\text { Capacidade de aprender rapidamente novos } \\
\text { conceitos e tecnologias. }\end{array}$ & 1,0 & 8,0 & 10,0 & 1,9 \\
\hline Criatividade. & 2,0 & 8,0 & 10,0 & 1,9 \\
\hline $\begin{array}{l}\text { Capacidade de lidar com incertezas e } \\
\text { ambigüidades. }\end{array}$ & 2,0 & 8,0 & 10,0 & 1,9 \\
\hline $\begin{array}{l}\text { Domínio de novos conhecimentos técnicos } \\
\text { associados ao exercício do cargo ou função } \\
\text { ocupada. }\end{array}$ & 2,0 & 8,0 & 10,0 & 1,8 \\
\hline Capacidade de inovação. & 2,0 & 8,0 & 10,0 & 1,8 \\
\hline Iniciativa de ação e decisão. & 3,0 & 8,0 & 10,0 & 1,6 \\
\hline Auto-controle emocional. & 3,0 & 8,0 & 10,0 & 1,6 \\
\hline Capacidade empreendedora. & 0,0 & 8,0 & 10,0 & 2,1 \\
\hline $\begin{array}{l}\text { Capacidade de lidar com situações novas e } \\
\text { inusitadas. }\end{array}$ & 2,0 & 8,0 & 10,0 & 1,7 \\
\hline Visão de mundo ampla e global. & 1,0 & 7,0 & 10,0 & 2,0 \\
\hline
\end{tabular}

FONTE - Dados da Pesquisa.

\section{Avaliação da modernidade organizacional}

Em relação à Modernidade Organizacional, os resultados indicam um patamar que pode ser caracterizado como moderado $(6,0)$, tendo os fatores Modernidade Política $(5,7)$ e Modernidade Administrativa e das Práticas de Gestão de Pessoas $(5,8)$ revelado-se como os mais críticos.

Em uma análise por fator, há que se salientar quanto à Modernidade Administrativa e das Práticas de Gestão de Pessoas, uma elevada percepção dos respondentes quanto à ênfase das orga nizações em resultados e no compartilhamento de seus propósitos e metas. Sobressai, também, a percepção quanto aos estímulos ao estabelecimento de ambientes de trabalho que favoreçam a comunicação e integração entre as pessoas, mesmo de níveis hierárquicos diferentes.

Por outro lado, aspectos associados às práticas de gestão, propriamente ditas, como a existência de sistemas de avaliação que permitam diferenciar o bom e o mau desempenho, de sistemas de remuneração que premiem os atos de competência e de práticas de recursos humanos que estimulem as pessoas a se preocuparem com a aprendizagem contínua, apresentam-se com os menores escores (TAB. $3)$. 
Tabela 3 - Análise descritiva - Modernidade Administrativa e das Práticas de Gestão de Pessoas

\begin{tabular}{|l|c|c|c|c|}
\hline Modernidade Administrativa e das Práticas de & \multicolumn{4}{|c|}{ Medidas Descritivas } \\
\cline { 2 - 5 } Gestão de Pessoas & Mínimo & Mediana & Máximo & d.p. \\
\hline $\begin{array}{l}\text { A organização é fortemente orientada para } \\
\text { resultados }\end{array}$ & 0,0 & 8,0 & 10,0 & 2,6 \\
\hline $\begin{array}{l}\text { A estratégia, missão, objetivos e metas da } \\
\text { organização são claramente definidos }\end{array}$ & 0,0 & 7,0 & 10,0 & 2,6 \\
\hline $\begin{array}{l}\text { De modo geral, os empregados sabem o que } \\
\text { devem fazer para colaborar com os objetivos da } \\
\text { organização }\end{array}$ & 0,0 & 7,0 & 10,0 & 2,2 \\
\hline $\begin{array}{l}\text { O ambiente de trabalho facilita o relacionamento } \\
\text { entre as pessoas, mesmo de níveis hierárquicos } \\
\text { diferentes }\end{array}$ & 0,0 & 7,0 & 10,0 & 2,2 \\
\hline $\begin{array}{l}\text { A organização equilibra adequadamente a } \\
\text { preocupação com resultados financeiros, com as } \\
\text { pessoas e com a inovação }\end{array}$ & 0,0 & 6,0 & 10,0 & 2,4 \\
\hline $\begin{array}{l}\text { A organização combina de forma equilibrada a } \\
\text { utilização de tecnologias avançadas com a } \\
\text { criatividade das pessoas }\end{array}$ & 0,0 & 6,0 & 10,0 & 2,3 \\
\hline $\begin{array}{l}\text { A tecnologia empregada favorece a interação } \\
\text { entre pessoas e áreas }\end{array}$ & 0,0 & 6,0 & 10,0 & 2,3 \\
\hline $\begin{array}{l}\text { A organização admite a diversidade de } \\
\text { comportamentos e respeita as diferenças } \\
\text { individuais }\end{array}$ & 0,0 & 6,0 & 10,0 & 2,2 \\
\hline $\begin{array}{l}\text { As políticas e práticas de recursos humanos da } \\
\text { organização estimulam o desenvolvimento } \\
\text { pessoal e profissional }\end{array}$ & 0,0 & 6,0 & 10,0 & 2,4 \\
\hline $\begin{array}{l}\text { As políticas e práticas da organização estimulam } \\
\text { que as pessoas estejam sempre bem informadas e } \\
\text { atualizadas }\end{array}$ & 0,0 & 6,0 & 10,0 & 2,2 \\
\hline $\begin{array}{l}\text { Os principais critérios para promoção são a } \\
\text { competência e a prod utividade da pessoa }\end{array}$ & 0,0 & 6,0 & 10,0 & 2,6 \\
\hline $\begin{array}{l}\text { Há um sistema de avaliação que permite } \\
\text { diferenciaro bom e o mau desempenho }\end{array}$ & 0,0 & 5,0 & 10,0 & 2,8 \\
\hline $\begin{array}{l}\text { O sistema de remuneração da organização } \\
\text { recompensa os atos de competência }\end{array}$ & 0,0 & 5,0 & 10,0 & 2,9 \\
\hline $\begin{array}{l}\text { As políticas e práticas de recursos humanos } \\
\text { estimulam as pessoas a se preocuparem com a } \\
\text { aprendizagem contínua }\end{array}$ & 0,0 & 5,0 & 10,0 & 2,5 \\
\hline
\end{tabular}

FONTE - Dados da Pesquisa.

Já no que tange à dimensão cultural nota-se, pelos dados apresentados na TAB. 4, concordância, por parte de percentual significativo de respondentes de encorajamento, pelas organizações, de climas internos que estimulem a iniciativa, a responsabilidade individual, a aprendizagem contínua, a criatividade e a auto-realização. 
Tabela 4 - Análise descritiva - Indicadores de Modernidade Cultural

\begin{tabular}{|l|c|c|c|c|}
\hline \multicolumn{2}{|c|}{ Modernidade Cultural } & \multicolumn{4}{|c|}{ Medidas Descritivas } \\
\cline { 2 - 6 } & Mínimo & Mediana & Máximo & d.p. \\
\hline $\begin{array}{l}\text { A organização encoraja a iniciativa e } \\
\text { responsabilidade individual }\end{array}$ & 0,0 & 7,0 & 10,0 & 2,2 \\
\hline $\begin{array}{l}\text { O clima interno da organização estimula que as } \\
\text { pessoas estejam em contínuo processo de } \\
\text { aprendizagem, no seu dia-a-dia de trabalho }\end{array}$ & 0,0 & 7,0 & 10,0 & 2,2 \\
\hline $\begin{array}{l}\text { O clima interno da organização estimula idéias } \\
\text { novas e criativas }\end{array}$ & 0,0 & 6,0 & 10,0 & 2,1 \\
\hline $\begin{array}{l}\text { Na organização há um clima estimulante para } \\
\text { que as pessoas realizem suas atividades, } \\
\text { buscando se superar }\end{array}$ & 0,0 & 6,0 & 10,0 & 2,1 \\
\hline
\end{tabular}

FONTE - Dados da Pesquisa.

Paradoxalmente, constata-se, quanto à dimensão política, menor nível de percepção dos pesquisados quanto à existência de processos de tomada de decisão participativos, descentralizados, transparentes, assim como de ações organizativas que favoreçam maior autonomia para a tomada de decisões (TAB. 5). Tais achados sugerem, não obstante os esforços para o estabelecimento de climas mais abertos à inovação e à aprendizagem, um caráter organizacional ainda autoritário, hierarquizado e centralizado.

Tabela 5 - Análise descritiva - Modernidade Política

\begin{tabular}{|l|c|c|c|c|c|}
\hline \multicolumn{4}{|c|}{ Modernidade Polítca } & \multicolumn{4}{|c|}{ Medidas Descritivas } \\
\cline { 2 - 6 } & Mínimo & Mediana & Máximo & d.p. \\
\hline $\begin{array}{l}\text { No que se refere ao aspecto político, o regime } \\
\text { que vigora na organização pode ser } \\
\text { caracterizado como democrático }\end{array}$ & 0,0 & 6,0 & 10,0 & 2,4 \\
\hline $\begin{array}{l}\text { A organização conta com sistemas de gestão } \\
\text { participativos que estimulam a iniciativa e } \\
\text { ação das pessoas }\end{array}$ & 0,0 & 6,0 & 10,0 & 2,2 \\
\hline $\begin{array}{l}\text { Os processos de tomada de decisão são } \\
\text { participativos e transparentes }\end{array}$ & 0,0 & 5,0 & 10,0 & 2,3 \\
\hline $\begin{array}{l}\text { O processo decisório na orga nização é } \\
\text { descentralizado }\end{array}$ & 0,0 & 5,0 & 10,0 & 2,5 \\
\hline $\begin{array}{l}\text { A organização favorece a autonomia para } \\
\text { tomar decisões }\end{array}$ & 0,0 & 5,0 & 10,0 & 2,3 \\
\hline
\end{tabular}

FONTE - Dados da Pesquisa.

\section{Avaliação da satisfação do trabalhador no e com o trabalho}

Em relação à satisfação no trabalho, os dados do estudo indicam no em um grau que também pode ser caracterizado como moderado $(5,8)$, cabendo destacar a satisfação com fatores associados ao trabalho 
em si $(6,9)$ como a dimensão mais bem avaliada. Já os fatores associados ao ambiente organizacional $(5,5)$ e à qualidade da gerência $(5,0)$ mostram se como os mais fracamente avaliados.

Quanto aos fatores associados ao trabalho em si, os dados da TAB. 6 indicam maior satisfação com aspectos, tais como: variedade de habilidades, significado do trabalho e qualidade do interrelacionamento. Por outro lado, o volume de trabalho apresenta-se como a variável mais mal avaliada.

Tabela 6 - Análise Descritiva - Satisfação com Fatores Associados ao Trabalho em Si

\begin{tabular}{|l|c|c|c|c|}
\hline \multicolumn{1}{|c|}{ Satisfação com Fatores Associados ao } & \multicolumn{3}{|c|}{ Medidas Descritivas } \\
\cline { 2 - 5 } Trabalho em Si & Mínimo & Mediana & Máximo & d.p. \\
\hline $\begin{array}{l}\text { Meu trabalho exige que eu utilize diversas } \\
\text { habilidades complexas e de alto nível } \\
\text { A oportunidade de ajudar outras pessoas } \\
\text { enquanto estou trabalhando }\end{array}$ & 1,0 & 8,0 & 10,0 & 2,0 \\
\hline $\begin{array}{l}\text { As pessoas com quem eu me relaciono e } \\
\text { convivo em meu trabalho }\end{array}$ & 2,0 & 8,0 & 10,0 & 1,7 \\
\hline $\begin{array}{l}\text { Meu trabalho me fornece consideráveis } \\
\text { oportunidades de independência e liberdade } \\
\text { sobre como executá- lo }\end{array}$ & 0,0 & 7,0 & 10,0 & 2,2 \\
\hline $\begin{array}{l}\text { A possibilidade de crescimento pessoal e de } \\
\text { desenvolvimento que eu tenho ao realizar o } \\
\text { meu trabalho }\end{array}$ & 0,0 & 7,0 & 10,0 & 2,4 \\
\hline $\begin{array}{l}\text { A liberdade de pensamento e ação que eu tenho } \\
\text { ao fazer o meu trabalho } \\
\text { A simples execução das tarefas do meu } \\
\text { trabalho oferece muitas oportunidades } \\
\text { (feedbacks) para mostrar a mim mesmo (a) se o } \\
\text { estou realizando bem ou não }\end{array}$ & 0,0 & 7,0 & 10,0 & 2,1 \\
\hline $\begin{array}{l}\text { O grau de participação que me é permitido nas } \\
\text { decisões importantes em relação ao meu } \\
\text { trabalho }\end{array}$ & 0,0 & 7,0 & 10,0 & 2,3 \\
\hline $\begin{array}{l}\text { O grau em que aplico no dia-a-dia do meu } \\
\text { trabalho os conhecimentos adquiridos ao longo } \\
\text { de minha formação acadêmica }\end{array}$ & 0,0 & 7,0 & 10,0 & 2,5 \\
\hline O volume de trabalho que eu tenho que realizar & 0,0 & 6,5 & 10,0 & 2,3 \\
\hline
\end{tabular}

FONTE - Dados da Pesquisa.

No que se refere, por sua vez, à satisfação com fatores organizacionais, observa-se pela TAB. 7, baixos graus de satisfação com aspectos tais como o modo como os conflitos são resolvidos nas empresas e a maneira como as mudanças e inovações organizacionais são implementadas. 
Tabela 7 - Análise descritiva - Satisfação com Fatores Organizacionais Anderson de Souza Sant’anna - Lúcio Flávio Renault de Moraes - Zélia Miranda Kilimnik

\begin{tabular}{|l|c|c|c|c|}
\hline \multicolumn{2}{|c|}{ Satisfação com Fatores Organizacionais } & \multicolumn{4}{|c|}{ Medidas Descritivas } \\
\cline { 2 - 5 } & Mínimo & Mediana & Máximo & d.p. \\
\hline $\begin{array}{l}\text { As comunicações e o modo como as } \\
\text { informações circulam na organização }\end{array}$ & 0,0 & 6,0 & 10,0 & 2,2 \\
\hline $\begin{array}{l}\text { A forma como os meus esforços são } \\
\text { valorizados pela organização }\end{array}$ & 0,0 & 6,0 & 10,0 & 2,2 \\
\hline $\begin{array}{l}\text { O modo como os conflitos são resolvidos na } \\
\text { organização }\end{array}$ & 0,0 & 5,0 & 10,0 & 2,1 \\
\hline $\begin{array}{l}\text { A maneira como as mudanças e inovações são } \\
\text { implementadas na empresa }\end{array}$ & 0,0 & 5,0 & 10,0 & 2,1 \\
\hline
\end{tabular}

FONTE - Dados da Pesquisa.

Já quanto à satisfação com a gerência observam-se baixos escores para aspectos como feedback e a existência de ações de coaching (TAB 8).

Tabela 8 - Análise descritiva - Satisfação com a Gerência

\begin{tabular}{|l|c|c|c|c|}
\hline \multicolumn{1}{|c|}{ Satisfação com a Gerência } & \multicolumn{4}{|c|}{ Medidas Descritivas } \\
\cline { 2 - 5 } & Mínimo & Mediana & Máximo & d.p. \\
\hline $\begin{array}{l}\text { Os meus superiores quase nunca me dizem } \\
\text { como estou me saindo na execução do meu } \\
\text { trabalho }\end{array}$ & 0,0 & 5,0 & 10,0 & 3,0 \\
\hline $\begin{array}{l}\text { Comumente os meus superiores me falam } \\
\text { sobre o que eles pensam a respeito do meu } \\
\text { desempenho no trabalho }\end{array}$ & 0,0 & 5,0 & 10,0 & 2,7 \\
\hline
\end{tabular}

FONTE - Dados da Pesquisa.

\section{SÍNTESE DOS RESULTADOS E CONCLUSÕES}

Como produtos da análise das propriedades psicométricas das escalas propostas, a análise da dimensionalidade indicou o agrupamento dos indicadores destinados à mensuração das competências individuais requeridas em um único fator, abrangendo os quinze indicadores propostos, o que, de certa forma, revela-se coerente com o próprio conceito de competência, entendida como a capacidade de o indivíduo mobilizar múltiplos saberes, conhecimentos, habilidades, com vistas ao alcance dos resultados esperados.

Já os indicadores de modernidade organizacional e de satisfação no trabalho puderam ser agrupados em fatores distintos. Os indicadores de modernidade organizacional, nos fatores denominados modernidade administrativa e das práticas de gestão de pessoas, modernidade política e modernidade cultural e os indicadores de satisfação no trabalho, nos fatores satisfação com fatores associados ao trabalho em si, satisfação com fatores organizacionais e satisfação com a gerência. 
Quanto à confiabilidade, os resultados dos cálculos do coeficiente alfa de Cronbach revelaram, para o conjunto dos fatores obtidos, uma fidedignidade dentro dos limites recomendados.

Já como resultados do diagnóstico das variáveis de interesse deste estudo, vale ressaltar a percepção dos profissionais pesquisados quanto a um elevado grau de demanda pelo conjunto das competências avaliadas vis-à-vis a prevalência de graus moderados de modernidade organizacional e satisfação com fatores de conteúdo e contexto do trabalho.

Em relação à elevada demanda pelo conjunto das competências investigadas, cabe resgatar observação de Gitahy e Fischer (1996) quanto à propagação de uma síndrome de construção de super-homens, identificada, pela dupla, em pesquisa junto a subsidiária brasileira de corporação multinacional, assim como em estudo conduzido por Luz (2001), em uma grande empresa nacional do setor de telecomunicações.

Quanto à analise das competências profissionais, convém destacar, também, a elevada demanda por competências descritas por Aubrum e Orofiamma (1991) como competências de terceira dimensão, as quais caracterizam-se não por serem habilidades manuais, nem conhecimentos técnicos, mas, antes, qualidades pessoais e relacionais.

No que tange à análise da modernidade organizacional, cabe ressaltar, não obstante os estímulos das organizações ao estabelecimento de climas internos mais favoráveis aos processos de aprendizagem contínuo, ao trabalho em equipe e às iniciativas de ação e decisão, a predominância de um caráter organizacional ainda autoritário, hierarquizado e centralizado.

Desse modo, coerentementemente com resultados obtidos em estudos realizados por Eboli (2001) e Kilimnik (2001), os achados deste estudo reforçam a necessidade de mudanças no comportamento das organizações, de modo que estruturas verticalizadas e centralizadas cedam espaço àquelas mais horizontais e descentralizadas, favorecedoras de maior autonomia, participação e envolvimento dos trabalhadores, o que pressupõe mudanças profundas na mentalidade organizacional.

Já em relação à satisfação no trabalho, cabe frisar os baixos escores atribuíd os a fatores associados à qualidade das gerências e a fatores organizacionais. Tais achados, acompanhados pelo grau de modernidade verificado junto à dimensão política, corrobora teses defendidas por Leite (1992) e Faoro (1992) de que a modernização em voga no país compreende um processo que, ainda hoje, pode ser definido como de modernização conservadora.

Em suma, pelo conjunto de dados obtidos, é possível concluir que as organizações têm demandado um amplo leque de competências, porém, em grau mais elevado com que se observa uma modernidade de suas políticas e práticas de gestão. De qualquer forma já se constatam movimentos na direção de maior fomento ao estabelecimento de climas organizacionais que estimulem importantes aspectos da modernidade como o trabalho em equipe e a iniciativa de ação e decisão. Fica, nesse sentido, a expectativa de que, desses movimentos, resulte massa crítica indispensável a um salto qualitativo na direção de uma efetiva modernidade organizacional, capaz de propiciar, para um número maior de trabalhadores, ambientes de trabalho mais satisfatórios.

Como limitações deste estudo, vale registrar a não obtenção da totalidade dos pressupostos à adoção de técnicas estatísticas multivariadas, tendo-se detectado, em específico, problemas quanto à premissa da normalidade. Em relação a esse aspecto, há que se considerar dificuldades apontados por Jonhson e Wichern (1998), em se obter, em ciências sociais, dados que se comportam exatamente seguindo uma 
distribuição normal. Na medida, todavia, em que nenhum dos fatores obtidos tenha apresentado discrepâncias com a literatura, cabe sugerir uma certa robustez das técnicas multivariadas, mesmo sem se ter atingido todos os seus pressupostos.

Outro problema enfrentado refere-se à ausência de critérios universalmente aceitos para avaliação dos resultados das análises multivariadas adotadas. Muito embora referenciados na literatura, via de regra, os valores de aceitação/rejeição variam de autor para autor, indicando a necessidade de maiores avanços nas pesquisas sobre o tema.

Além disso, reconhece-se que a exclusão de um número significativo de observações com dados ausentes e de outliers, muito embora possa propiciar maior robustez das análises multivariadas, pode, por outro lado, implicar em limitações quanto à generalidade dos achados.

Aventamos, assim, a importância de novos estudos que permitam confirmar ou refutar os resultados aqui obtidos junto a outros públicos e contextos, propiciando uma ampliação da cadeia nomológica das pesquisas envolvendo os construtos estudados.

\section{REFERÊNCIAS BIBLIOGRÁFICAS}

AUBRUN, S.; OROFIAMMA, S. Les compétences de troisième dimension. Paris: CFF-CNAM, 1991. (Relatório de Pesquisa).

BARTLETT, C. A.; GHOSHAL, S. The myth of the generic manager: new personal competencies for new management roles. California Management Review, v. 40, n. 1, p. 93-116, 1987.

BORGES-ANDRADE, J. E. Conceituação e mensuração de comprometimento organizacional. Temas em Psicologia: Psicologia Social e Organizacional, vol.1, 37-47, 1995.

BORGES-ANDRADE, J. E.; PILATI, R.; SILVINO A. M. D. Construção de um instrumento de análise de imagens organizacionais. In: XXVI Reunião Anual de Psicologia. Anais... Ribeirão Preto: SBP, 1996.

BOYATZIS, R. E. The competent manager: a model for effective perfo rmance. New York: John Wiley, 1982.

BUARQUE, C. A revolução nas prioridades: da modernidade técnica à modernidade ética. São Paulo: Paz e Terra, 1994.

CHURCHILL JR, G. A. A paradigm for developing better measures of marketing constructs. Journal of Marketing Research, v. 16, p. 64-73, Feb. 1979.

COOPER, C. L.; SLOAN, S. J.; WILLIAMS, J. Occupational stress indicator management guide. Windsor: NFER- Nelson, 1988.

DUBAR, C. A sociologia do trabalho frente à qualificação e à competência. Educação e Sociedade. Campinas, n. 64, p. 87-103, set. 1998. 
EBOLI, Marisa P. Modernidade na gestão de bancos. 1996. Tese (Doutorado em Administração) FEA/USP, São Paulo.

FAORO, R. A questão nacional: a modernização. Revista de Estudos Avançados, São Paulo, v. 6, n. 14, jan./abr. 1992.

FLEURY, A.; FLEURY, Maria Tereza L. Estratégias empresariais e formação de competências : um quebra-cabeça caleidoscópico da indústria brasileira. São Paulo: Atlas, 2001.

GITHAY, L. FISCHER, Rosa Maria. Produzindo a flexibilidade: algumas reflexõ es sobre as aventuras e desventuras da gerência pós-moderna. In: Congresso Latino Americano de Sociologia do Trabalho. Comunicações apresentadas... Águas de Lindoia: ALAST, 1996.

HACKMAN, J. R.; OLDHAM, G. R. Development of the job diagnostic survey. Journal of Applied Psychology, v. 60, n. 2, p. 159-170, 1975.

HAIR JR., J. F. et. al. Multivariate data analysis. New Jersey: Prentice Hall, 1998.

HIRATA, Helena. Alternativas sueca, italiana e japonesa ao paradigma fordista: elementos para uma discussão sobre o caso brasileiro. In: SOARES, R. (org.). Gestão da qualidade: tecnologia e participação. Brasília: Codeplan, 1992.

JOHNSON, R. A.; WICHERN, D. W. Applied multivariate statistical analysis. New Jersey: Prentice Hall, 1998.

KILIMNIK, Zélia M. Trajetórias e transições de carreiras profissionais de recursos humanos. 2000. Tese (Doutorado em Administração) - CEPEAD/UFMG, Belo Horizonte.

LE BORTEF, G. De la compétence: essai sur un attracteur étrange. Paris: Editions d'Organizations, 1994.

LEITE, Márcia P. A qua lificação reestruturada e os desafios da formação profissional. Novos Estudos. São Paulo, n. 45, p. 79-96, julho, 1996.

LUZ, Talita R. Telemar-Minas: Competências que marcam a diferença. 2001. Tese (Doutorado em Administração) - CEPEAD/UFMG, Belo Horizonte.

MALHOTRA, N. K. Pesquisa de marketing: uma orientação aplicada. Porto Alegre: Bookman, 2001.

MANFREDI, Silvia M. Trabalho, qualificação e competência profissional - das dimensões conceituais e políticas. Educação e Sociedade. Campinas: CEDES, n. 64, p. 13-49, set. 1998.

MARQUARDT, M. J.; ENGEL, D. W. Global human resource development. Englewood Cliffs: Prentice-Hall, 1993.

McCLELLAND, D. C.; DAILEY, C. Improving officer selection for the foreign service. Boston: McBer, 1972.

MORAES, L. F. R.; KILIMNIK, Zélia M. A qualidade de vida no trabalho burocrático automatizado. Belo Horizonte: CEPEAD/UFMG, 1989 (Relatório de Pesquisa). 
MOTTA, R. A busca da competitividade nas empresas. Revista de Administração de Empresas. São

Paulo, v. 35, n. 2, p. 12-16, mar./abr. 1992.

NUNNALLY, J. C.; BERNSTEIN, Ira H. Psychometric theory. New York: McGraw-Hill, 1994.

OLIVEIRA-CASTRO, Gardênia A. Percepção de suporte organizacional: desenvolvimento e validação de um questionário. XXII ENANPAD. Anais... Foz do Iguaçu: ANPAD, 1998.

PERRENOUD, P. Ensinar: agir na urgência, decidir na incerteza. Porto Alegre: Artmed, 2001.

PRAHALAD, C. K.; HAMEL, G. The core competence of the corporation. Harvard Business Review, v. 68, n. 3, p. 79-91, May/June 1990.

PUCIK, W.; THICHY, N. M.; BARNETT, C. K. Globalization and human resource Management: creating and leading the competitive organization. New York: John Wiley, 1992.

QUARSTEIN, V. A.; McAFEE, R. B.; GLASSMAN, M. The situational occurrences theory of job satisfaction. Human Relations, v. 45, n. 8, p. 859-73, 1992.

RICHARDSON, R. et al. Pesquisa social: métodos e técnicas. São Paulo: Atlas, 1985.

SANT'ANNA, A. S. Análise psicométrica de escalas em pesquisas em administração: procedimentos e resultados de validação de medidas de modernidade organizacional, competências individuais e satisfação no trabalho. In: XXVII ENANPAD. Anais... Atibaia: ANPAD, 2003.

SANT'ANNA, A. S. Competências individuais requeridas, modernidade organizacional e satisfação no trabalho: uma análise de organizações mineiras sob a ótica de profissionais da área de administração. 2002. Tese (Doutorado em Administração) - CEPEAD/UFMG, Belo Horizonte.

SHIROMA, E. O.; CAMPOS, R. F. Qualificação e reestruturação produtiva: um balanço das pesquisas em educação. Educação e Sociedade, Campinas, n. 61, p. 13-35, 1997.

SPENCER, L. M; SPENCER, S. Competence at work. New York: John Wiley, 1993.

STROOBANTS, M. Savoir-faire et compétence au travail. Bruxelles: Éditions de l'Université de Bruxelles, 1997.

TABACHINIK, Bárbara G.; FIDELL, Linda S. Using multivariate statistics. Boston: Allyn and Bacon, 2001.

TOURAINE, A. A crítica da modernidade. Petrópolis: Vozes, 1994.

WERTHER, W.; DAVIS, K. Administração de pessoal e recursos humanos. São Paulo: McGraw-Hill, 1983.

ZAJDSZNAJDER, L. Pós-modernidade e tendências da administração contemporânea. In: Boletim Técnico do SENAC, v. 19, n. 3, p. 10-9, set./dez. 1993.

ZARIFIAN, P. Objetivo competência: por uma nova lógica. São Paulo: Atlas, 2001. 
Artigo recebido em 21.11.2002. Aprovado em 08/03/2004.

\author{
Anderson de Souza Sant'anna \\ Professor da Fundação Dom Cabral e do Programa de Mestrado Profissional em Administração \\ Pucminas/FDC \\ Interesses de pesquisa nas áreas de gestão de competências, gestão de carreiras, gestão de talentos, \\ modernidade organizacional e qualidade de vida no trabalho. \\ E-mail: anderson@fdc.org.br \\ Endereço: Rua São Lázaro, 1.301/102, Sagrada Família, Bhte - MG, 31035-580.
}

\title{
Lúcio Flávio Renault de Moraes
}

Professor e Coordenador do Núcleo de Estudos Avançados em Comportamento Organizacional Interesses de pesquisa nas áreas de gestão de competências, gestão de carreiras, gestão de talentos, modernidade organizacional e qualidade de vida no trabalho.

E-mail: renault@face.ufmg.br

Endereço: Rua Curitiba, 832/1.101, Centro, Bhte - MG, 30000-000.

\section{Zélia Miranda Kilimnik}

Professora do Programa de Mestrado Profissional em Administração da FUMEC

Interesses de pesquisa nas áreas de gestão de competências, gestão de carreiras, gestão de talentos, modernidade organizacional e qualidade de vida no trabalho.

E-mail:kilimnik@globo.com

Endereço: Rua do Ouro, 1.920, apto 501A, Serra, Bhte - MG, 30210-590. 